\title{
A sea-level monopole in the equatorial Indian Ocean
}

\author{
Venugopal Thandlam $\mathbb{1}^{1,2 凶}$, Udaya Bhaskar T.V.S ${ }^{3}$, Rahaman Hasibur ${ }^{3}$, Paolo De Luca ${ }^{1,4}$, Erik Sahlée', Anna Rutgersson ${ }^{1}$, \\ Ravichandran $\mathrm{M}^{5}$ and Ramakrishna S.S.V.S ${ }^{2}$
}

In this study, we show the relationship between sea-level anomalies (SLA) and upper-ocean parameters in the Equatorial Indian Ocean (EIO). This work also focuses on the variability of SLA obtained from satellite altimeter data in different spatial and temporal scales and its relationship with computed ocean heat content $(\mathrm{OHC})$, dynamic height $(\mathrm{DH})$, and thermocline depth $\left(20^{\circ} \mathrm{C}\right.$ isotherm: D20) during 1993-2015. SLA showed low Pearson's correlation coefficient (CC) with upper-ocean parameters over central ElO resembling a "Monopole" pattern. The Array for Real-time Geostrophic Oceanography (ARGO) in situ profile data in the central ElO also confirmed this. SLA over this monopole showed low correlations with all parameters as compared with eastern and western EIO. These findings show a clear signature of a persisting sea-level monopole in the central EIO. Oscillating SLA over western and eastern ElO during summer and winter monsoon months is found to be responsible for locking this monopole in the central ElO. Both SLA and OHC increased in ElO during 2006-2015 compared with 1993-2005. The month of January showed different east-west trends at different times. This trend during 1993-2015 is neutral, but it shifted from negative during 1993-2005 to positive during 2006-2015.

npj Climate and Atmospheric Science (2020)3:25; https://doi.org/10.1038/s41612-020-0127-z

\section{INTRODUCTION}

The Equatorial Indian Ocean (EIO) is the second longest tropical ocean belt after the tropical Pacific. EIO extending from $40^{\circ} \mathrm{E}$ to $100^{\circ} \mathrm{E}$ and $10^{\circ} \mathrm{S}$ to $10^{\circ} \mathrm{N}$ has a great geographic, social, economic, and political importance. EIO plays an active role in global and regional climate change through ocean-atmosphere-coupled processes, and has a strong impact on many global and regional weather and climate patterns ${ }^{1}$, including the precipitation patterns over the surrounding land mass ${ }^{2}$. The key feature of the EIO is the strong air-sea interactions and the strong air-sea coupling shows spatial and temporal variations from intraseasonal to interannual scales. The western and eastern EIO plays a key role in the formation of the Indian Ocean Dipole $(\mathrm{IOD})^{3,4}$. It is well known that El Niño-Southern Oscillation (ENSO) has a global impact on climate ${ }^{5}$; in particular, the wind anomalies associated with ENSO extend up to the Indian Ocean, and in turn affect the basin-wide circulation ${ }^{6}$. Saji et al. ${ }^{3}$ comprehensively described the IOD, and subsequent works recognized IOD and ENSO as the two dominant modes of interannual climate variability in the Indian Ocean. IOD coupled with ENSO determines the strength of the Indian summer monsoon rainfall (ISMR) ${ }^{7-10}$. EIO also plays a key role in exchanging heat by transporting warm waters from the Pacific to the Indian Ocean through the Indonesian Through Flow, thereby hosting the largest pool of warm waters of the global oceans ${ }^{11}$. The impact of IOD and ENSO on the Indian Ocean circulation, particularly in the EIO, has also received substantial attention ${ }^{6}$.

Being an integral part of ElO, the Arabian Sea Mini Warm Pool ${ }^{12}$ in the southeastern Arabian Sea, and the Madden Julian Oscillation (MJO) in the central EIO, have pivotal implications on the ISMR. Lower atmospheric and upper-ocean states over EIO significantly control the exchange of heat and momentum fluxes between the northern and southern Indian Ocean ${ }^{13}$. Equatorially trapped surface, subsurface currents, and counter currents coupled with wind-forced Rossby waves and Kelvin waves over $\mathrm{EIO}$ are responsible for different physical regimes in the Indian Ocean $^{14}$. Strong Wyrtki jet over the western and eastern EIO during pre- and post monsoon, respectively, uplifts the thermocline at the west and sinks the thermocline at its eastern terminus, thus causing changes in the water mass structure in the $\mathrm{EIO}^{15}$.

The EIO acts as a bridge between the southern and the northern Indian Ocean (as well as the Arabian Sea and the Bay of Bengal) in exchanging the waters through advection, thereby changing water properties (density and temperature) of these basins. Thus, the EIO shows both negative and positive feedbacks through strong coupling with the atmosphere. Both these feedbacks show temporal and spatial variations through remote and local forcing, and indeed affect the regional and global weather patterns ${ }^{16,17}$. IOD and MJO are some of the ocean-atmosphere-coupled phenomena affected by variations in these forcing and feedback mechanisms, and thus induce significant changes in the tropical weather patterns. North-South subsurface dipole is another mode of variability observed in the tropical Indian Ocean, caused by subsurface temperature change and resembling the patterns of IOD (both phases) and El Niño co-occurrence years ${ }^{18}$. Cloud cover, winds, radiation fluxes, precipitation, and evaporation are the atmospheric parameters that influence the $\mathrm{EIO}^{19,20}$. Surface and subsurface ocean currents, turbulent fluxes, and heat transfer due to advection are the oceanic processes guiding the dynamics of the $\mathrm{EIO}^{21}$. Both weather and climate anomalies coupled with changes in upper- ocean dynamics and the lower atmosphere have a strong impact on the Indian Ocean rim countries. Hence, presently there is a strong focus on understanding the dynamics of EIO in more detail by the weather and climate forecasting community.

A direct measure to know the upper-ocean variability is to study sea-level anomalies (SLA), sea surface temperature (SST), upperocean heat content $(\mathrm{OHC})$, and thermocline depth (D20), which

\footnotetext{
${ }^{1}$ Department of Earth Sciences, Uppsala University, Uppsala, Sweden. ${ }^{2}$ Department of Meteorology and Oceanography, Andhra University, Visakhapatnam, India. ${ }^{3}$ Indian National Center for Ocean Information Services, Ministry of Earth Sciences, Hyderabad, India. ${ }^{4}$ Geography and Environment, Loughborough University, Loughborough, UK. ${ }^{5}$ National Centre for Polar and Ocean Research, Goa, India. ${ }^{凶}$ email: venux4@gmail.com
} 
have a direct or indirect relationship among themselves. For example, many physical oceanographic studies consider changes in SLA to understand the dynamics of the upper ocean ${ }^{22-24}$. SLA is a proxy to oceanic phenomena (e.g., warm/cold-core eddies and upwelling/downwelling). SLA also has a direct relationship with the potential temperature, $\mathrm{OHC}$, and density of the ocean's layers. As SLA is a function of thermosteric height, it defines the thermal expansion of the deep ocean and upper layers of the ocean due to varying heat and density. The EIO receives high solar radiation throughout the year, and the shift in the thermal equator, twice a year, cause changes in the wind patterns (south/north) over the Inter-Tropical Convergence Zone (ITCZ) ${ }^{25}$. These changes cause anomalous SST over this region at different temporal scales. Thermocline depth, coupled with strong mixing and upwelling, guides the SST and changes the SLA and OHC. High SST, OHC, and subsequent deeper thermocline have physical and biological effects, with an impact on surface and subsurface processes ${ }^{26}$. Positive and negative feedback mechanisms between SST and lower atmospheric fluxes bring continuous change in the ocean's state in this region.

The global oceans are observed to warm in the recent past owing to natural and anthropogenic causes. Several studies showed enhanced SLA and OHC in the global oceans, including the Indian Ocean ${ }^{13,27,28}$. Thermal expansion of the warm ocean and freshwater addition from melting continental ice in the past

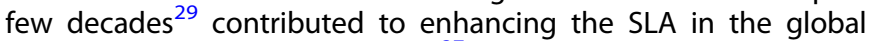
oceans. A study from Nerem et al. ${ }^{27}$ estimated the climate changedriven acceleration of global mean sea level over the last 25 years to be $0.084 \pm 0.025 \mathrm{~mm} / \mathrm{yr}^{2}$ using a 25 -year time series of precision satellite altimeter data from TOPEX/Poseidon, Jason-1, Jason-2, and Jason-3. Their results emphasized the increase in global sealevel rise in these same 25 years as $2.9 \mathrm{~mm} / \mathrm{yr}$. This linear rise rate in SLA is coupled with the average climate change acceleration. It is, however, alarming that this study projected global mean sealevel rise of $65 \pm 12 \mathrm{~cm}$ by 2100 compared with 2005, with a simple extrapolation of the quadratic function. These findings are similar to the Intergovernmental Panel on Climate Change (IPCC) 5th Assessment Report (AR5) (https://www.ipcc.ch/assessmentreport/ar5/) model projections.

The difference between increased global warming and constant global mean surface temperatures has increased in the recent decades ${ }^{30,31}$, and will lead to anomalous heat flux into the ocean $^{32-37}$. From many studies, it is understood that the eastern Pacific Ocean stores a significant portion of heat missing from the atmosphere due to the presence of cold SST and transports this into the Indian Ocean, through the Indonesian Through Flow, causing the Indian Ocean to warm deeper into the subsurface ${ }^{38,39}$.

The global sea-level rise is not spatially uniform, and it increases over a region, while it decreases over the other. Rates of sea-level rise observed are different owing to the difference in data products and the period of study. Sea-level rise may attain values as high as $10 \mathrm{~mm} / \mathrm{yr}$ in regions like the western tropical Pacific. There is indeed a significant sea-level rise in the northern Indian Ocean and western Pacific during recent years ${ }^{29,40-43}$. It is this regional sea-level variability that is of immediate importance while assessing the societal impacts of coastal and low-lying regions. Hence, regional sea-level variability ought to be considered as a superposition of global mean sea-level rise and regional ocean dynamics. Although the regional sea-level variability is primarily caused by natural climatic variability ${ }^{28,44}$, a rapidly changing climate of the Earth can influence a region's sea level in numerous ways. Timmermann et al. ${ }^{45}$ showed that regional features of sealevel trends in the tropical Indo-Pacific can be attributed to the changes in the prevailing wind-stress patterns. Han et al. ${ }^{28}$ also emphasized on the importance of wind-driven mass distribution in explaining the observed trend patterns. They also showed a significant decreasing trend of sea level in the southwest TIO region (which rebounds during the last decade). Their study also concluded that the observed trends of sea level (for the period 1961-2008) are due to enhanced Hadley and Walker circulation of the warming Indian Ocean and its associated surface wind-stress changes and Ekman pumping velocities. Nidheesh et al. ${ }^{46}$ reported that the decadal sea-level fluctuations in the eastern $\mathrm{EIO}$ and the Bay of Bengal are primarily due to wind-stress variations, whereas wind-stress curl is a major contributing factor to the rise in sea level in the southern Indian Ocean. Furthermore, there are many observational studies that indicate that sea level has been rising at a rate of $2.5 \mathrm{~mm} / \mathrm{yr}$ along the coastline of India since the $1950 \mathrm{~s}$, as compared with the global mean sea-level rise of $1.8 \mathrm{~mm} / \mathrm{yr}$ from 1961 to $2003^{47}$.

In situ and satellite observations of Indian Ocean sea level, combined with climate-model simulations, identified a distinct spatial pattern of sea-level rise relative to the $1960 \mathrm{~s}^{28}$. The same study by Han et al. ${ }^{28}$ also found that sea level has decreased substantially in the southern TIO and increased elsewhere in the Indian Ocean. This enhanced Indian Ocean warming over the western Indian Ocean potentially weakened the land-sea thermal contrast and dampened the summer monsoon over parts of South Asia in the recent decades ${ }^{48,49}$. Changes in atmosphere and ocean circulation affect this regional sea-level rise. Srinivasu et al. ${ }^{13}$ show a distinct reversal of the north Indian Ocean (north of $5^{\circ} \mathrm{S}$ ) sealevel decadal trend between 1993-2003 and 2004-2013 using various satellite and in situ observations, ocean reanalysis products, and model simulations. The decadal change in surface winds over the Indian Ocean altered the surface- turbulent heat flux and meridional heat transport at $5^{\circ} \mathrm{S}$. These changes caused the sea level to fall during 1993-2003 and rise during 2004-2013. The upper-ocean- (thermosteric sea level of $700 \mathrm{~m}$ ) dominated steric height explains most of the observed reversal and the spatial patterns of sea-level change.

Sea-level variability and SST in the EIO are strongly coupled with ENSO and IOD in the Indo-Pacific sector ${ }^{6,50,51}$. While IOD evolution is controlled by equatorial ocean dynamics forced by zonal winds, subsurface variability in the tropical Pacific guides the evolution of ENSO $^{52}$. Rao et al. ${ }^{53}$ found that the dominant mode of interannual variability in the TIO can be explained by total sea-level variance $(46 \%)$ and the total heat-content variance (39\%). Mohapatra et al. ${ }^{54}$ studied the multidecadal to decadal variability of subsurface temperature in the eastern EIO and the mechanism forcing it. They concluded that wind forcing and ocean dynamics associated with it, is the major factor, emphasizing the importance of local atmospheric forcing. In the past, many studies were undertaken to understand the role of ENSO and IOD on the sea-level variability in the Indian Ocean ${ }^{50,55,56}$. The difference in sea level in the Pacific Ocean and Indian Ocean is observed to be the main cause for Indonesian Throughflow. While occurrence of ENSO results in SLA variations over the Pacific, variations in SLA between western Pacific and eastern Indian Ocean result in transport of Indonesia Throughflow ${ }^{57}$. Though ENSO and IOD are modes of climate variability pertaining to the Indian Ocean, their signatures differ over the Indian Ocean. During an IOD event, the dipole signature is clearly seen within sea-level data with the sea level falling (rising) in the eastern (western) tropical Indian Ocean ${ }^{3,4}$. The ENSO, IOD difference extends temporally, with IOD events being phaselocked to the seasonal cycle with anomalous values occurring during boreal summer and fall, while for ENSO, the anomalies appear during winter and spring ${ }^{50}$.

Limited tide gauge and altimeter observation data led Deepa et al. $^{58}$ to use Ocean General Circulation Model (OGCM) simulations and ocean reanalysis data to explore the interannual variability of sea level in the Indian Ocean. Their analysis revealed that the co-occurrence of IOD and ENSO contributed significantly toward the interannual variability in sea level in the Indian Ocean, in comparison with occurrence of pure IOD or El Niño events. Their study found that the sea-level variability is characterized by constant generation of open-ocean downwelling, with maximum 
signals in the $10^{\circ} \mathrm{S}-5^{\circ} \mathrm{S}$ region. They also concluded that the decadal variability in the ENSO is primarily responsible for the decadal sea-level variability in the Indian Ocean by modulating Indonesian Throughflow transport. Hence, advance and accurate forecasting of ENSO and IOD are essential in improving understanding of long-term SLA variability and forecasting in the Indian Ocean.

There is an ongoing work to improve OGCMs to better understand and model the upper-ocean dynamics of the EIO and ocean-atmospheric coupling ${ }^{59}$. A recent study by Rahaman et al. ${ }^{60,61}$ showed persistent errors on the improved operational ocean model surface currents, temperature, and salinity over the EIO, compared with observations. These errors were attributed to the biases in observations and poor model representation of the EIO upper-ocean dynamics. The variability of SLA over the EIO has a pivotal role in different ocean-atmospheric phenomena in this part of the global ocean ${ }^{17}$. SLA gives reliable information on dynamic height $(\mathrm{DH}), \mathrm{OHC}$, and $\mathrm{D} 20$, and is useful in estimating the mixed-layer temperatures and depth supported by temperature profiles. Information from SLA is also valuable to study the upper ocean overturning circulation and mesoscale ocean eddies. Hence, assimilating data from various ocean-observing platforms for different parameters would significantly reduce the model bias and thus improve the model performance. Enhanced model physics with improved data assimilation into the models could improve high-resolution forecasting. Temperature and salinity profile data up to $200 \mathrm{~m}$ below the surface from Array for RealTime Geostrophic Oceanography (ARGO) ${ }^{62}$ in the Indian Ocean contribute to reduce the forecast error in regional and global models. Combined information from ARGO and sea-level observations could enhance the ocean-monitoring capacity. Moreover, a robust relationship between sea level and other physical upperocean parameters is essential to reduce errors in sea-state and climate forecasting. Hence, here we study the relationships between upper-ocean parameters and SLA over the EIO.

Rebert et al. ${ }^{63}$ attempted a similar study over different locations in the tropical Pacific between $15^{\circ} \mathrm{N}$ and $15^{\circ} \mathrm{S}$ using observational datasets. The study found that the thermocline variations are in good agreement with sea-level changes, and these variations would further allow to observe the changes in the upper-layer volume. These upper-layer changes are also significant with the changes in $\mathrm{OHC}$ and $\mathrm{DH}$. If the ocean is idealized into the twolayer system, $\mathrm{OHC}$ is proportional to the upper-layer depth $D$ as $\mathrm{OHC} \sim D\left(T_{1}-T_{2}\right)$ where $T_{1}$ and $T_{2}$ are the temperatures of the upper layer and motionless lower layer, respectively. While $\mathrm{DH}$ is approximated as $\mathrm{DH} \sim D\left(\rho_{2}-\rho_{1}\right) / \rho_{1}$, where $\rho_{1}$ and $\rho_{2}$ are upperand lower-layer thickness, respectively ${ }^{64}$. DH and SLA computed from the different observing platforms correlate well if the thermal structure of the upper ocean resembles a two-layer model. More details on the two-layer system and its limitations are discussed in Rebert et al. $^{63}$. Two-layer system assumption works well to approximate geostrophic flow ${ }^{64-66}$. The relationship between the slope of isotherms and that of the sea surface is useful to estimate the geostrophic flow. Rebert et al. ${ }^{63}$ had not focused on the spatial variability of these parameters over tropical Pacific, except for a few scattered locations between $15^{\circ} \mathrm{N}$ and $15^{\circ} \mathrm{S}$. On the other hand, Ali and Sharma ${ }^{67}$ identified an El Niño kind of phenomenon in the EIO sea-level and oceanic thermal masses using the Geosat altimeter-derived sea-level observations for the 1987-1988 period. This study discussed the sea surface oscillations from west to east due to the equatorial jet and reversal of monsoonal winds during these years. Despite this study, the EIO EI Niño kind of phenomenon has gained little attention.

Motivated by these studies, we aim at studying the relationships between SLA, DH, OHC, and D20 over the ElO. Hence, we hope that our work will further enhance the knowledge on upperocean variability over the EIO, particularly the relationship between SLA and the upper-ocean parameters mentioned above.
Our work also uses observations to find the relatively stable central EIO compared with seasonally oscillating eastern and western EIO. The paper is organized as follows: Section 2 describes the results obtained, followed by discussion in Section 3. In the end, Section 4 contains data and methods used in the study.

\section{RESULTS}

Spatial variability and correlations between SLA, OHC, DH, and D20 over the EIO

We computed the mean and standard deviations of SLA, DH, OHC, and D20 to quantify their spatial variability. The eastern EIO shows the highest SLA $(3.3-3.5 \mathrm{~cm})$, followed by Seychelles-Chagos thermocline ridge (SCTR) close to $10^{\circ} \mathrm{S}$ in the southern Indian Ocean. The SCTR is important for the climate of this region as it hosts the thermocline ridge and has a key role in ocean dynamics ${ }^{68}$ (Fig. 1a). The SCTR region shows both interannual and decadal sea-level variations ${ }^{69,58}$. Changes in the depth of the ridge control the convection and evaporation and hence, the amount of precipitation falling during ISMR $^{49}$. High SLA values over eastern EIO are expected as this region is part of the IndoPacific warm pool ${ }^{11}$. Both $\mathrm{OHC}$ and D20 (Fig. 1b, d) show similar patterns with high mean values north of the equator and low mean values in the south. DH shows a well-established gradient from eastern to western EIO, having a low over the SCTR region (Fig. 1c). All parameters (including SLA) show a low standard deviation over the central EIO $\left(5^{\circ} \mathrm{S}-5^{\circ} \mathrm{N}\right)$ (Fig. 1e-h). Hence, this feature establishes what we define a "Monopole" pattern over $5^{\circ}$ $\mathrm{S}-5^{\circ} \mathrm{N}, 65^{\circ} \mathrm{E}-85^{\circ} \mathrm{E}$, and is more prominent for SLA and OHC. Mean and standard deviations of these upper-ocean parameters show high seasonal variability (Supplementary Figs 1 and 2, of supplementary material) over eastern and western EIO; however, persisting low over central EIO has no seasonal changes.

The correlations between SLA and other upper-ocean parameters show a similar "Monopole" signature, with low correlation values over central EIO. The correlation between SLA and DH (Fig. 2a) has a better agreement than SLA_OHC (Fig. 2b) and SLA_D20 (Fig. 2c). Hence, provided accurate temperature and salinity profiles are available, computation of $\mathrm{DH}$ in the $\mathrm{EIO}$ approximates well the SLA in this region. Central EIO shows relatively low correlations $(0.4-0.7)$ between DH and SLA, which emphasize the dynamic nature of this region associated with the upper ocean. Both DH and SLA are useful variables for determining the topography of the sea surface, calculation of geostrophic currents, and transports relative to the upper layer of the ocean ${ }^{66}$. Thus, these parameters provide information about the ocean's circulation. Although the SLA and DH are highly correlated, there are a few limitations corresponding to this coupling. The baroclinic dependence of $\mathrm{DH}$ varies slowly in time as compared with the barotropic nature of SLA, which is more energetic and varies with shorter timescales ${ }^{63}$. Thus, only lowfrequency comparisons can be made and are possible between these two parameters, which led us to compare the climatological means computed from the monthly data. The mean and standard deviations of both SLA and DH in the central EIO have low variability and make these parameters more stable over this region. Generally, low or asynchronous variability of a parameter with respect to each other, would lead to low correlations between these two parameters. This stable SLA over the central EIO is also observed in the monthly trends computed by averaging $\mathrm{SLA}$ from $5^{\circ} \mathrm{S}$ to $5^{\circ} \mathrm{N}$ along $40^{\circ} \mathrm{E}-100^{\circ} \mathrm{E}$. We discuss this in more detail in the following section. These low correlations could be due to the selected reference depth. In this case, $300 \mathrm{~m}$ would not be sufficient to compute $\mathrm{DH}$ due to the deep bathymetry over this region. Hence, we have repeated the analysis by computing $\mathrm{DH}$ and $\mathrm{OHC}$ using different reference depths $(500,700$, and $1000 \mathrm{~m})$ (figures not shown). The results 


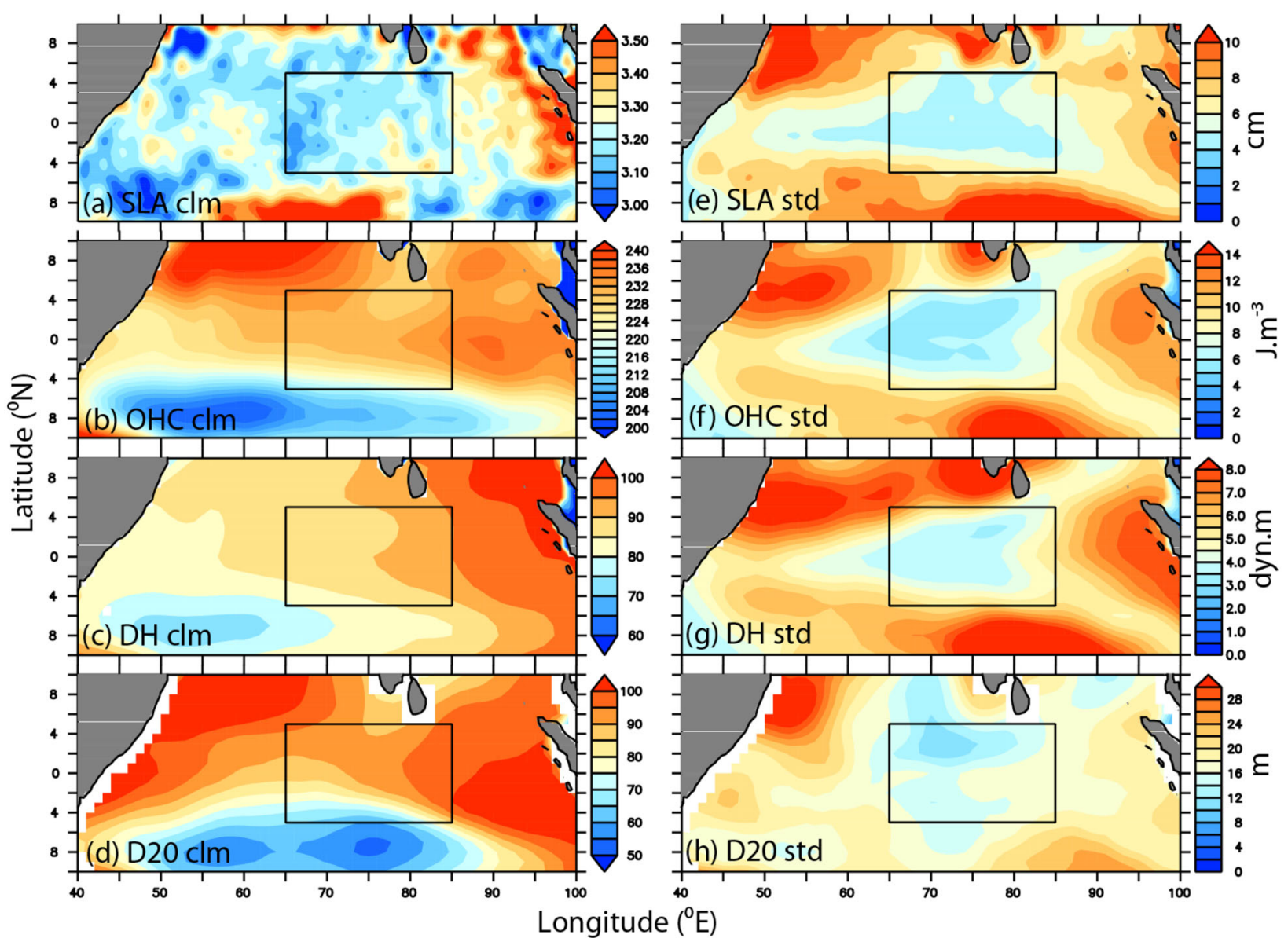

Fig. 1 Climatology (a-d) and standard deviations (e-h) of SLA, OHC, DHT, and D20, respectively. The rectangular boxes show the central EIO $\left(5^{\circ} \mathrm{S}-5^{\circ} \mathrm{N} ; 65^{\circ} \mathrm{E}-85^{\circ} \mathrm{E}\right)$.

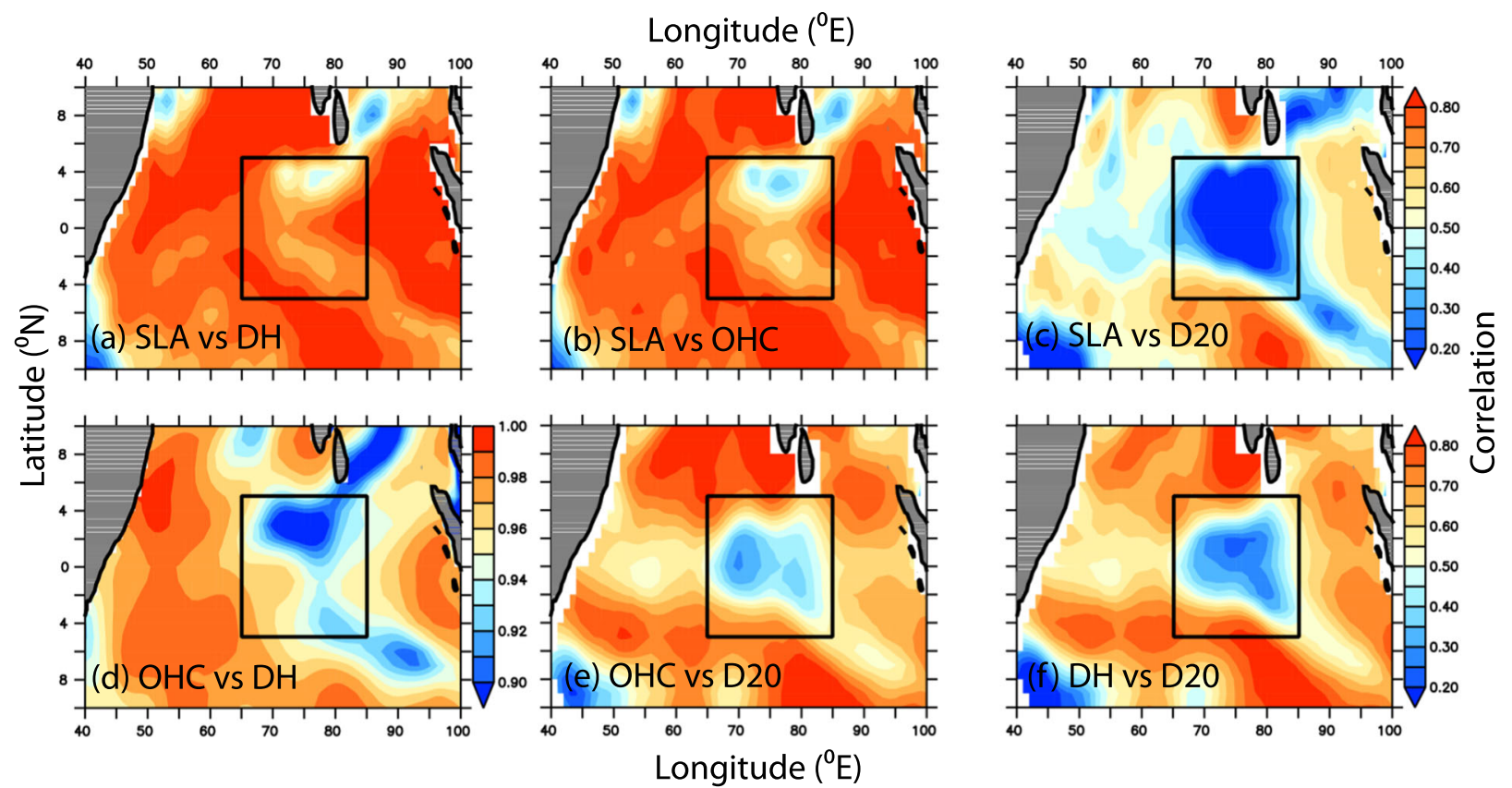

Fig. 2 Pearson's correlations among SLA, OHC, DH, and D20. The rectangular boxes show the central ElO region $\left(5^{\circ} \mathrm{S}-5^{\circ} \mathrm{N} ; 65^{\circ} \mathrm{E}-85^{\circ} \mathrm{E}\right)$. 


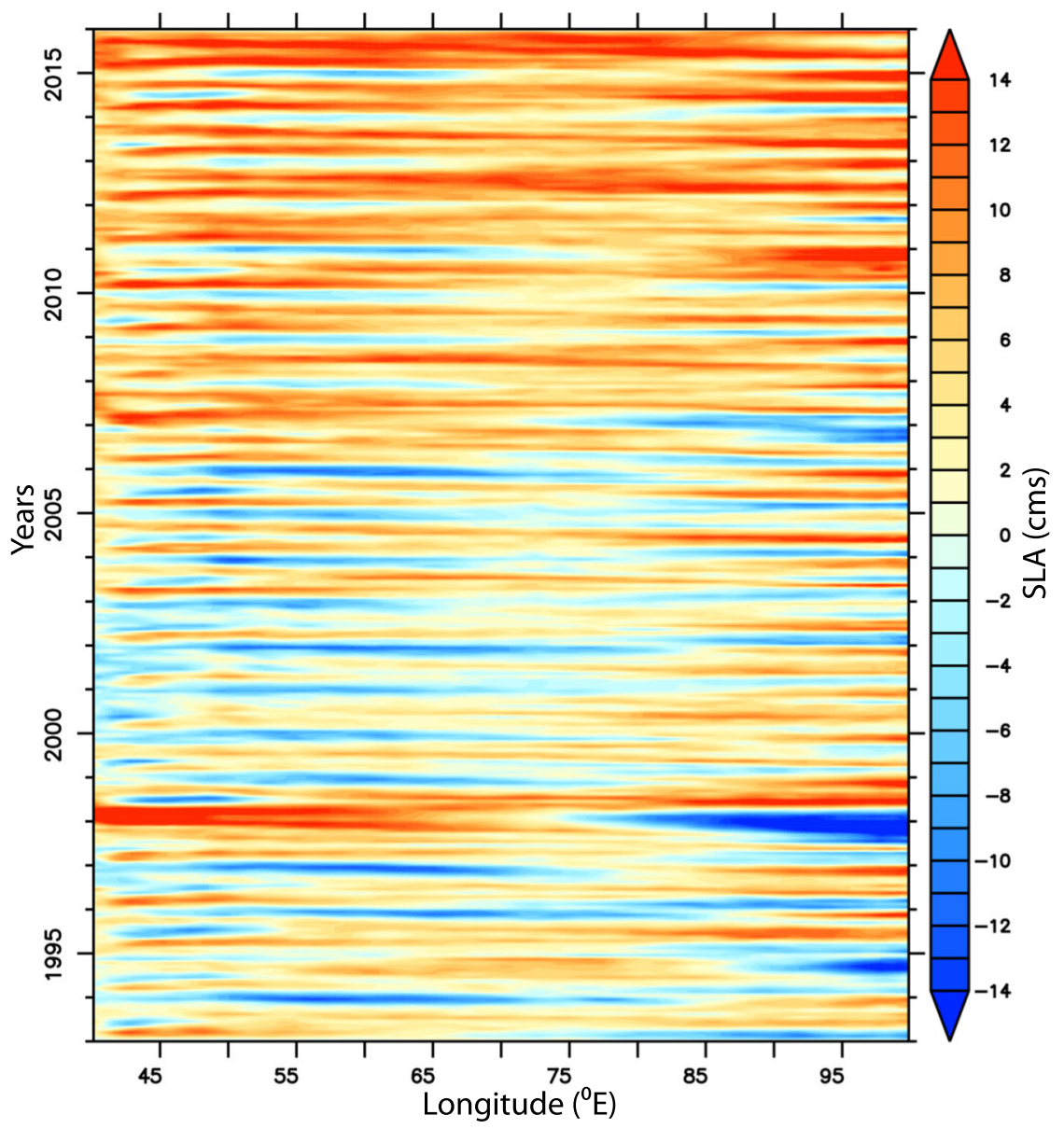

Fig. 3 Monthly mean SLA. Monthly averaged SLA from $5^{\circ} \mathrm{S}$ to $5^{\circ} \mathrm{N}$ along $40^{\circ} \mathrm{E}-100^{\circ} \mathrm{E}$ during $1993-2015$.

\begin{tabular}{|c|c|c|c|c|c|c|}
\hline Depth & SLA_DH & SLA_OHC & SLA_D20 & OHC_DH & OHC_D20 & DH_D20 \\
\hline 300 & 0.72 & 0.67 & 0.28 & 0.94 & 0.53 & 0.49 \\
\hline 500 & 0.72 & 0.67 & 0.28 & 0.94 & 0.50 & 0.47 \\
\hline 700 & 0.72 & 0.68 & 0.28 & 0.93 & 0.49 & 0.46 \\
\hline 1000 & 0.70 & 0.68 & 0.28 & 0.92 & 0.44 & 0.45 \\
\hline
\end{tabular}

presented in Table 1 show no significant changes in the correlations with other depths used in the study. Despite the changes in the $\mathrm{OHC}$ and $\mathrm{DH}$ reference depths, D20 remains constant, and hence the correlations between SLA and D20 do not change. It means that the depth below $300 \mathrm{~m}$ over this region is not static to mimic the two-layer model of the upper ocean. Hence, we used common reference depth $(300 \mathrm{~m})$ for computing both $\mathrm{DH}$ and $\mathrm{OHC}$ in the EIO. Thus, the two-layer assumption over the central EIO has some uncertainties associated with the study of upper-ocean parameters.

SLA and OHC show high Pearson's correlation values over the EIO, except in its central region (Fig. 2b), which has Pearson's correlation coefficient between 0.4 and 0.6. Although the $\mathrm{OHC}$ is obtained by integrating temperature from the surface to a reference depth, the noise in the temperature profiles could cause biases in $\mathrm{OHC}$. Moreover, $\mathrm{DH}$ is a function of both temperature and salinity, and would cause more noise in its computation, which further leads to lower Pearson's correlation values with SLA. Correlations between SLA and D20 show an interesting spatial signature. One-centimeter rise in SLA would deepen the D20 by $2 \mathrm{~m}^{63}$, and a $2^{\circ} \mathrm{C}$ change in the subsurface temperature leads to $16-\mathrm{m}$ change in $\mathrm{D} 20^{70}$, thus causing a negative correlation, which is very prominent over the central EIO. However, in other regions, when SLA increased, D20 shallowed. This could be due to the differences in shortwave radiation received and changes in the upper-ocean dynamics over the $\mathrm{EIO}^{25,71,72}$. In another way, irrespective of changing SLA over the central EIO, D20 shows no variability (Fig. 3 and Supplementary Fig. 10). OHC as a function of temperature shows lower SLA_OHC correlations (Fig. 2b) than SLA_DH (Fig. 2a) in central EIO. But the noise in both temperature and salinity is here negligible as the data used have monthly resolution and they span a sufficiently long period. Thus, OHC over central EIO may not be very reliable for estimating the SLA and vice versa, due to rapidly changing upper-ocean dynamics over the region.

Monitoring of tropical warm-water pools, water properties, and their displacement is important for many climate studies. Such characteristics are less difficult to disentangle when the thermocline variations are well correlated with the SLA ${ }^{73,74}$. The Pearson's correlation between SLA and D20 over the central EIO is 0.2 (Fig. 2c), which is lower compared with SLA_DH and SLA_OHC. The lower correlation is also persistent from the southeastern Indian Ocean to the central EIO and into the Bay of Bengal (BoB). But, the lowest correlations over central EIO still preserve the monopole pattern. The spatial correlations of OHC_DH (Fig. 2d), OHC_D20 
Table 2. Correlations between SLA_OHC, SLA_ DHT, and SLA_ D20 from south to north in the central EIO.

\begin{tabular}{lllll}
\hline S. No. & WMOID & SLA (vs) DH & SLA (vs) OHC & SLA (vs) D20 \\
\hline 1 & 2900672 & 0.94 & 0.95 & 0.96 \\
2 & 2900673 & 0.93 & 0.94 & 0.94 \\
3 & 2900674 & 0.87 & 0.84 & 0.88 \\
4 & 2900676 & 0.83 & 0.82 & 0.87 \\
5 & 2900677 & 0.68 & 0.61 & 0.82 \\
6 & 2900678 & 0.5 & 0.61 & 0.74 \\
7 & 2900679 & 0.58 & 0.72 & 0.82 \\
8 & 2900680 & 0.56 & 0.70 & 0.81 \\
9 & 2900681 & 0.82 & 0.93 & 0.91 \\
10 & 2900682 & 0.96 & 0.96 & 0.95 \\
\hline \multicolumn{7}{l}{ Rows 5 and 6 show lower values obtained from the floats deployed in the } \\
central ElO.
\end{tabular}

(Fig. 2e), and DH_D20 (Fig. 2f) over the EIO are also included in this study. These correlations have similar patterns as discussed earlier, and highlight the lower correlations (0.2-0.4) over central EIO surrounded by higher values $(>0.6)$. There is a sharp thermocline near the equator, and a two- or 1.5-layer model usually can be applied to study upper-ocean variability. These results emphasize that the thermocline depth considered $(300 \mathrm{~m})$ over the central EIO does not represent the two-layer model and demands to consider much shallower/deeper thermocline depth. There is a direct relationship between the correlation of SLA and the mean depth of the thermocline. This means that the shallow thermocline depth well approximates the two-layer model of the upper ocean and thus better correlates with SLA. The shallow thermocline with a higher slope would well represent the two-layer structure and fluctuations in the SLA. Despite shallow D20 over central EIO than the surrounding regions (Supplementary Fig. 10), SLA shows low correlations with D20 over this region. This again emphasizes complex upper-ocean dynamics over the central EIO. While the correlations plotted between SLA and D20 are significant at $90 \%$, all other correlations among different upperocean parameters are significant at $99 \%$ (Fig. 2).

\section{ARGO observations over $10^{\circ} \mathrm{S}-5^{\circ} \mathrm{N}$}

The Pearson's correlations computed between SLA_OHC, SLA_DHT, and SLA_D20 using the ARGO observations from INCOIS are given in Table 2 , and the corresponding scatter plots are given in the supplementary material (Supplementary Fig 3-5). Correlations from the daily (high-frequency) ARGO observations are in agreement with those from the gridded data over the central EIO. All the upper-ocean parameters, i.e., OHC, DHT, and D20, act as a better proxy to SLA both in the south (correlations: $0.95,0.94$, and 0.96 ) and north (correlations: $0.96,0.96$, and 0.95) (Table 2) of the central EIO. However, they show lower correlations (0.61, 0.5, and 0.74) (Table 2) close to the equator. Despite the fact that all three parameters showed similar results (Table 2), SLA has stronger correlations with D20 than with $\mathrm{OHC}$ and DHT near the equator. These results exemplify the typical nature of the central EIO and the existence of the SLA monopole. Although the monopole is locked between east-west sea-level oscillations over the EIO, the impacts of both Rossby and Kelvin waves are also essential to understand its structure, evolution, and existence. The semiannual SLA variability in the EIO (between $10^{\circ} \mathrm{S}$ and $10^{\circ} \mathrm{N}$ ) is characterized by a basin mode, involving Rossby and Kelvin waves traveling back and forth. The masking of these waves with each other due to interference leads to an amphidrome of phase propagation at the center of the $\mathrm{EIO}^{75}$. The characteristics of the low correlations in the central EIO could be due to the resonance of this masking by Kelvin and Rossby waves. The annual characteristic of this low also depends on the coexisting concurrent amphidromes with opposite rotation sharing the cophase from September to February ${ }^{76}$. Hence, it is also essential to investigate if the monopole is rotatory or oscillatory. However, this study is aimed at just reporting the monopole, rather than focusing on the nature of its characteristics, and this would be taken in future works.

\section{Temporal variability of SLA over EIO}

Several recent studies highlighted the changing SLA over the EIO. Ali and Sharma ${ }^{67}$ identified that bimodal oscillation of SLA slopes, averaged over $5^{\circ} \mathrm{N}-5^{\circ} \mathrm{S}$ along $40^{\circ} \mathrm{E}-100^{\circ} \mathrm{E}$ in the EIO, occurs due to the reversal of monsoon winds and currents. However, the study used only 1 year (1987-1988) of altimeter observations, which make the results fragile. Webster et al. ${ }^{4}$ observed similar phenomena in both SST and SLA during the 1997-1998 period over $5^{\circ} \mathrm{N}-5^{\circ} \mathrm{S}$. This study reported that these anomalies in SLA and SST correspond to changes in propagation characteristics of a Rossby wave. Thus, we performed a similar study with long-term monthly SLA data to check the persistence of these oscillations, and to find the impact of these oscillations along the EIO. This analysis is useful to find the extent of oscillations and stability of the SLA over central EIO, as observed in the spatial maps of mean and standard deviation. For this purpose, we focused on the temporal (monthly) variability of SLA (Fig. 3), OHC, DH, and D20 (Supplementary Figs $8-10$ ) over $5^{\circ} \mathrm{N}-5^{\circ} \mathrm{S}$ along $40^{\circ} \mathrm{E}-100^{\circ} \mathrm{E}$.

Monthly SLA anomalies over the EIO are shown in Fig. 3. Monthly SLA averaged over $5^{\circ} \mathrm{N}-5^{\circ} \mathrm{S}$ along $40^{\circ} \mathrm{E}-100^{\circ} \mathrm{E}$ shows persistent low values over western EIO during the onset of monsoon (Jun-Sep) and high values during spring and fall (Fig. 3). A different phenomena is observed with high SLA over the eastern EIO during the same period. This contrast in SLA shows that the EIO is exhibiting dipole pattern during the ISMR and winter monsoon with a low occurring over the western and a high over the eastern EIO. The anomalous behavior, caused by the strong reversal of winds over western EIO, could decrease the thermocline depth due to upwelling ${ }^{13}$. In addition, transport of warm water from the western to the eastern EIO, due to wind-driven currents, Wyrtki jet ${ }^{15}$, and fast-moving Kelvin waves during spring, deepens the thermocline in the eastern EIO, causing the subsurface heat to increase, and leading to high SLA in the subsequent season. Although these oscillations are consistent throughout, interannual variations are seen during 1993-2005. The low SLA over the western EIO damped after 2005, and the EIO shows an increase in SLA from west to east. Despite the regular sea-level low during 1993-2005, the period from 2006 to 2015 comprises three of such low sea-level events during 2010, 2011, and 2015 (Fig. 3), which could have been influenced by IOD and ENSO. For example, the 1997 strong positive IOD coupled with ENSO has significantly reduced the correlations among upper ocean parameters over the monopole (figure not shown). On the other hand, though there was a regular sea-level low during spring and winter months of every year (Fig. 3) even after 2005, during 2010, 2011, and 2015, this low has been amplified. Both 2010 and 2011 have the impact of IOD triggered by strong La Niña ${ }^{77}$. It is evident that negative IOD with or without the impact of ENSO causes negative sea-level anomalies in the western Indian Ocean, which may further extend toward western EIO during later months ${ }^{3,4}$. At the same time, late 2014 also witnessed negative IOD, whose impact can be seen over western EIO in the beginning of $2015^{78}$. The EIO gained significant heat (Fig. 4 and Supplementary Fig. 8) during the same period 2006-2015. In particular, eastern EIO shows a large OHC increase during 2006-2015 (Supplementary Fig. 8). However, the DH and D20 patterns (Supplementary Figs 9, 10) over the EIO were preserved. In particular, DH and D20 over the central EIO are more 


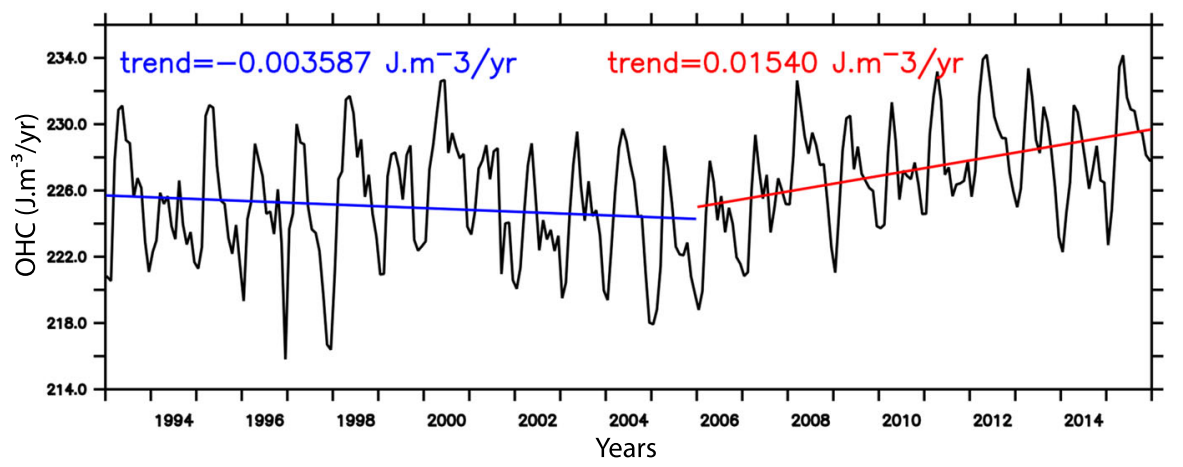

Fig. $4 \mathrm{OHC}$ trend averaged from $5^{\circ} \mathrm{S}$ to $5^{\circ} \mathrm{N}$ and $40^{\circ} \mathrm{E}$ to $100^{\circ} \mathrm{E}$ during $1993-2015$. The blue line shows the trend during $1993-2005$ and the red line corresponds to the period 2006-2015.

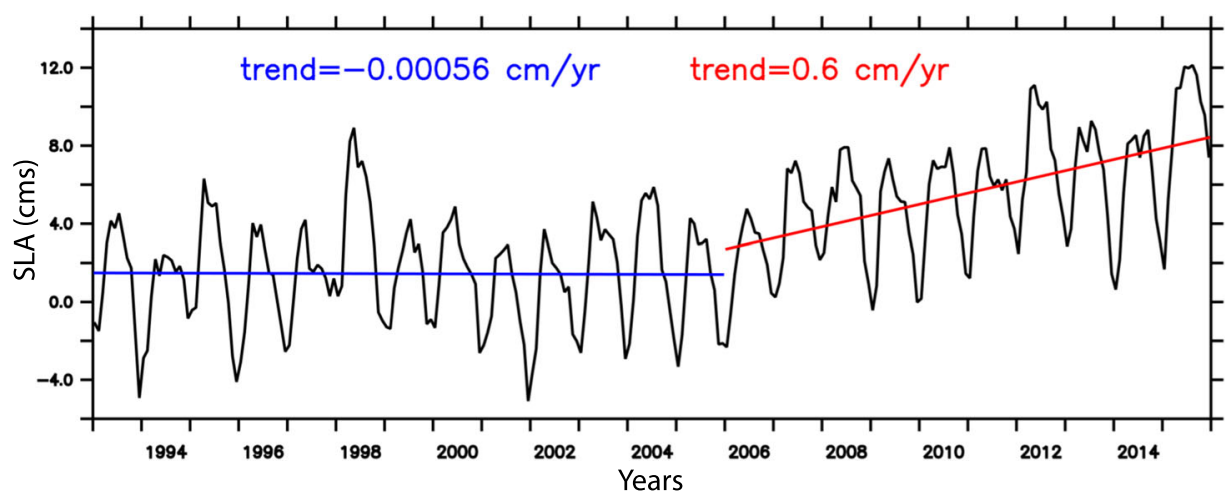

Fig. 5 SLA trend averaged from $5^{\circ} \mathrm{S}$ to $5^{\circ} \mathrm{N}$ and $40^{\circ} \mathrm{E}$ to $100^{\circ} \mathrm{E}$ during $1993-2015$. The blue line shows the trend during $1993-2005$ and the red line corresponds to the period 2006-2015.

stable in the study period. In contrast, SLA and OHC show an increase in the central EIO during 2006-2015. La Niña during 2010-2011 and El Niño during 2014-2015 may be responsible for these changes in the OHC and SLA over the EIO. This increase in $\mathrm{OHC}$ and SLA in the EIO during 2006-2015, further decreased the correlations among upper-ocean parameters over the monopole (Supplementary Fig. 11).

OHC (Fig. 4 and Supplementary Fig. 8) and SLA (Fig. 5) trend analysis further illustrates this increase over the EIO after 2005. The SLA averaged over $5^{\circ} \mathrm{N}-5^{\circ} \mathrm{S}$ along $40^{\circ} \mathrm{E}-100^{\circ} \mathrm{E}$ is consistent from 1993 to 2005 with the annual trend of $\sim 0 \mathrm{~cm} / \mathrm{yr}$. However, the 2006-2015 period shows an increased SLA of $0.6 \mathrm{~cm} / \mathrm{yr}$. Increasing $\mathrm{OHC}$ in the ocean layers induces thermal expansion ${ }^{79}$. Thus, this increase in SLA is attributed to OHC increase over the EIO ${ }^{13}$. The central EIO has a similar magnitude of increase in both SLA (Supplementary Fig. 6) and OHC (Fig. 4). Monthly mean trends of SLA averaged over $5^{\circ} \mathrm{N}-5^{\circ} \mathrm{S}$ along $40^{\circ} \mathrm{E}-100^{\circ} \mathrm{E}$ are shown for three different time periods in Fig. 6. Steeper trends during 2006-2015 (blue) correspond to an increase in SLA and OHC. Trends during 1993-2005 (black) are weaker, and the magnitude of trends during 1993-2015 (magenta) lies in-between. These trends are "negative" during February-April (1st mode) and August-October (2nd mode), and switched to "positive" during May-July and November-January. As pointed before, the equator-trapped waves and seasonal variations in the $W_{y r t i}$ jet ${ }^{15}$ may have caused these variations. These seasonal variations (oscillations) of the SLA during each period at both ends of the equator hold the SLA over the central EIO between them and cause it to vary less or make central EIO a more stable region, thus preserving the monopole pattern. Similarly, a spatial map of these mean trends for the three different time periods is shown in Fig. 7. Solid lines represent positive trends and dashed lines negative trends. These trends have interannual variations (figures not shown), and the results agree with Ali and Sharma ${ }^{67}$. All the parameters show the impact of extremes associated with IOD and ENSO. For example, SLA shows a clear increase (decrease) over the western (eastern) EIO during the strong positive IOD of 1997-1998 and 2006-2007 (Fig. 3). The $\mathrm{OHC}, \mathrm{DH}$, and D20 have similar signatures (Supplementary Figs 8-10). In summary, the EIO shows an oscillating dipole pattern in SLA, and this pattern changed after 2005 with a persistent increase in OHC and SLA over this region. During the same time, the central EIO (Monopole) shows an increase in SLA due to a rise in $\mathrm{OHC}$; however, the $\mathrm{DH}$ and $\mathrm{D} 20$ remain stable. This disturbance in the dipole mainly attributed to $\mathrm{OHC}$ rise can be linked to regional changes in the atmospheric and ocean phenomena. The abrupt change after 2005 in the ElO could also be linked to damped wind stress, upwelling, and changes in the thermocline depth over this region ${ }^{13}$.

\section{DISCUSSION}

We studied the variability of SLA with upper-ocean parameters such as $\mathrm{OHC}, \mathrm{DH}$, and D20 in the EIO. We used a long-term (1993-2015) low-frequency (monthly) data to find the correlations of SLA on these parameters. SLA shows higher correlations with $\mathrm{OHC}$ and $\mathrm{DH}$. However, the correlations show lower values with respect to D20. The SLA over the central EIO $\left(5^{\circ} \mathrm{S}-5^{\circ} \mathrm{N}, 65^{\circ} \mathrm{E}-85^{\circ} \mathrm{E}\right)$ shows lower correlations with all the parameters, and resembles a "Monopole". As mentioned before, we chose 300-m depth as the sea-level fluctuations reflect density changes above $400 \mathrm{~m}$, and the "Monopole" feature is also persistent with $\mathrm{OHC}$ and $\mathrm{DH}$ computed with respect to other depths (e.g., 500, 700, and $1000 \mathrm{~m}$ ). The analysis carried out with in situ observations from ARGO data over this region is also in agreement with the gridded 


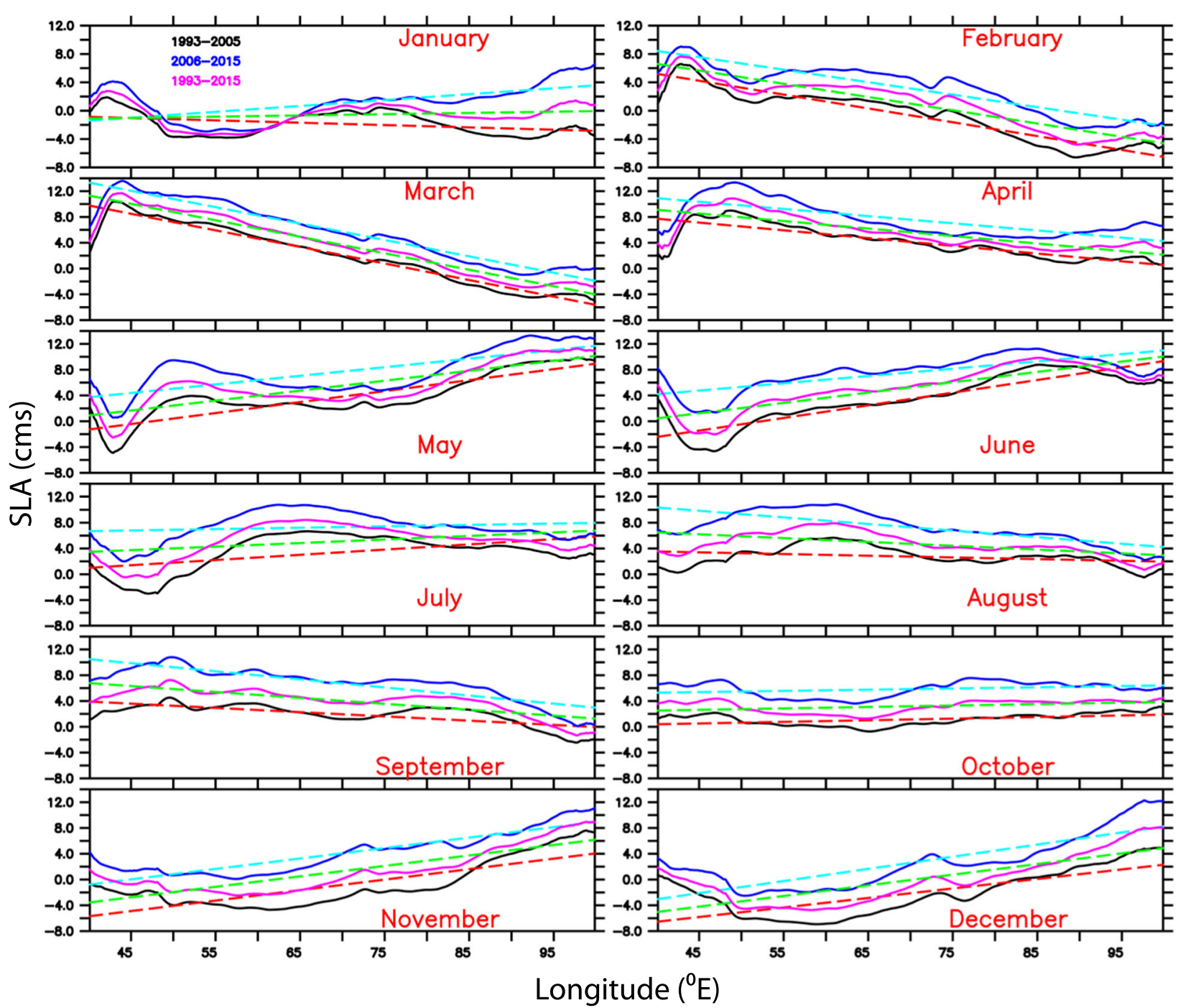

Fig. 6 Climatic monthly SLA trends averaged from $5^{\circ} \mathrm{S}$ to $5^{\circ} \mathrm{N}$ along $40^{\circ} \mathrm{E}-100^{\circ} \mathrm{E}$. Black, blue, and magenta lines represent the periods 1993-2005, 2006-2015, and 1993-2015, respectively. The red, green, and light-blue dashed lines are the corresponding trends.
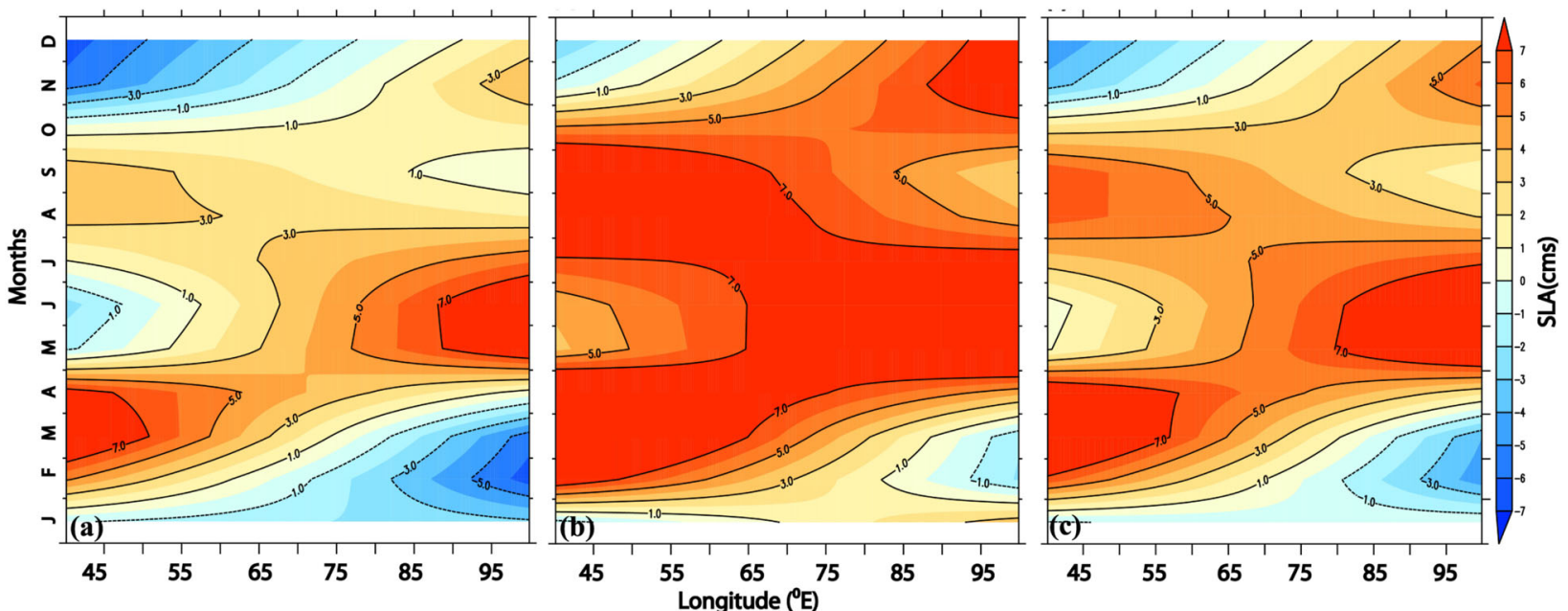

Fig. 7 Climatic monthly SLA trends. Climatic monthly SLA trends averaged from $5^{\circ} \mathrm{S}$ to $5^{\circ} \mathrm{N}$ along $40^{\circ} \mathrm{E}-100^{\circ} \mathrm{E}$ for the periods a $1993-2005$, b 2006-2015, and c 1993-2015. 
data. All the parameters $(\mathrm{OHC}, \mathrm{DH}$, and $\mathrm{D} 20)$ from the observations showed higher correlations over north and south of the equator as compared with the center. These low correlations of SLA with OHC over the central EIO are linked to the dynamical nature of the upper ocean, rather than with the noise in the temperature profiles used to compute the OHC and SLA. Low-frequency changes in $\mathrm{DH}$ could lead to low correlations with rapidly changing SLA. The baroclinic nature of $\mathrm{DH}$ depends on the accurate temperature-salinity relationship. It is most likely that the first baroclinic mode dominantly contributes to $\mathrm{SLA}^{80}$. Although D20 is shallow over central EIO (Supplementary Fig. 10), the lower correlations of SLA with D20 over this region could be due to the violation of the two-layer model in the upper ocean, and involve complex upper-ocean dynamics. These results agree with Rebert et al. ${ }^{63}$, where the correlations between SLA_DH and SLA_OHC are better than the correlation between SLA and D20 in the tropical Pacific Ocean. Observed low correlations in a belt from the southeastern Indian Ocean to the central EIO and into the BoB are in disagreement with Rebert et $\mathrm{al}^{63}$. Furthermore, contrary to Rebert et al. ${ }^{63}$ based on scattered locations in the equatorial Pacific, our study showed spatial dependence of SLA with upperocean parameters, including the correlations among upper-ocean parameters computed with respect to different reference depths in the EIO. On the other hand, the SLA shows higher correlations over both ends of the EIO. This relationship between SLA and upper-ocean parameters breaks in the central EIO and fades toward northern regions due to the increased thickness of the thermocline. Our study highlighted the limitations in the two-layer assumption over the EIO and thus the existence of "Monopole" in the central EIO. Also, a major difference from Rebert et al. ${ }^{63}$ is that the bimodal oscillations of SLA over the EIO are dominated by the strong winds and equator-trapped waves. These variations coupled with the seasonal changes in the fresh and saline water inputs from BoB and Arabian Sea, respectively, causing SLA to vary baroclinically and thus affecting the correlations.

This low correlations' belt can be linked to the exchange of surface water between the Indian Ocean and western Pacific through Indonesian Through Flow, in which wind and currents play a key role in transporting the waters in and out of the EIO and BoB. The slow-moving equatorial Rossby waves could also be responsible for these low correlations. The tropical Pacific has a well-established two-layer upper ocean, and the tropical Indian Ocean does not. However, we expect these correlations to change with the seasons as the two-layer structure changes with change in temperature and salinity. Considering the deeper reference depth away from the equator (toward the north) may improve the correlations between SLA and other upper-ocean parameters. The low correlations over the monopole could be due to the wellmixed and rapidly changing upper ocean without a wellestablished thermocline, the large variability of temperature, salinity, and $\mathrm{OHC}$. The equatorial surface, subsurface, and counter currents ${ }^{6}$ over this region have a strong influence on these weak correlations. This region has also a strong influence from the coastal currents from both east and west coasts of Indian mainland, and acts as a mixing pool for high saline waters coming from the Arabian Sea and less salty or freshwater coming from the BoB. This mixing leads to rapid or high-frequency changes in both temperature and salinity, which further changes the upper-ocean dynamics. The winds and currents during both summer and winter monsoons have a significant impact on this region.

We observed that bimodal oscillation in SLA over the EIO leads to El Niño kind of phenomenon in the water mass and thermocline depths. Though the phenomenon resembles EI Niño, it is purely seasonal and it is here studied in the ocean's perspective. Hence, this comparison with ENSO might not be very obvious, as ENSO involves multiyear and large-scale coupled processes. Observed EIO phenomena are coupled with the strong monsoon cycle and equator-trapped ocean waves. Persistent low
SLA is observed during the onset of summer monsoon over the western Indian Ocean. Climatic monthly SLA over the EIO $\left(5^{\circ} \mathrm{S}-5^{\circ} \mathrm{N}\right.$ along $\left.40^{\circ} \mathrm{E}-100^{\circ} \mathrm{E}\right)$ shows "negative" trends in spring and fall, and "positive" trends in summer and winter. The eastern Indian Ocean shows opposite phenomena during the same periods. However, these trends exhibit interannual variability. The rapid increase in both SLA and OHC noticed in EIO during 2006-2015 leads to changes in the magnitudes of these trends. The increase in SLA after 2005 over the EIO dampened the low SLA over western EIO, but preserved these oscillations in trends. This increase in SLA is consistent over central EIO (Supplementary Fig. 6). These results are consistent during all months, except for January that shows different trends during different years. The trend in 1993-2015 is neutral during this month, and has a shift from negative (1993-2005) to positive (2006-2015). This illustrates the anomalous climatic behavior of SLA during January.

Both DH and D20 have less variability over the central EIO. The first two leading modes of interannual variability of SST in the EIO are governed by the IOD and ENSO, that in turn have also significant impacts on SLA and OHC. The subsurface dipole in the EIO is forced by wind- stress curl anomalies, driven mainly by meridional shear in the zonal wind anomalies and peaks during December-February (DJF), a season after the dipole mode index peaks ${ }^{18}$. The internal mode of variability of the EIO forced by IOD, but modulated by Pacific forcing, could lead to persistent sea-level monopole. The seasonal evolution of thermocline, subsurface temperature, and the corresponding leading modes of variability further support this hypothesis. The monopole region reported in the study coincides with the region of maximum salinity variability ${ }^{81}$, and so the role of freshening or salinity on the monopole in this area is significant. During the anomalous years such as IOD, the freshwater gets transported to this region, which may play an important role in controlling low variability of the upper-ocean parameters. So the SLA correlations with sea surface salinity would also give a better emphasis. Though it is not significant to focus on the region where SLA variability is small in amplitude, these persisting low correlations would lead to large biases in the numerical models. The barotropic mode contributes less to sea-level variability, and has too large spatial scale and too fast phase speed. It is unlikely that sea-level variability near the equator on the seasonal timescale is primarily associated with the barotropic mode. However, SLA over the central EIO appears to be barotropic. Our results need more attention via the study of baroclinic and barotropic processes using numerical models. Higher correlations of SLA in the eastern and western EIO are associated with large-scale ocean circulation ${ }^{75}$ and tidal amphidrome patterns in the Indian Ocean ${ }^{76}$. Moreover, bathymetry (deeper regions in the central basin show less variable parameters), and the importance of the shallower thermocline in coastal regions are considerable factors for these differences in the correlations. The role of Rossby and Kelvin waves and upperocean dynamics on the monopole are also worth investigating. It is essential to find the characteristics of this "monopole" in terms of its oscillation or rotation. Subsequent studies may aim at the role of deep-ocean expansion, solar radiation, and clouds' impact on the downwelling radiation, and on the variability of SLA over the EIO. In this study, we restrict the analyses to simply report the existence of the monopole, and all the above phenomena should be tested and verified using additional datasets and modeling efforts. Finally, the global temperature increased to about $1{ }^{\circ} \mathrm{C}$ during 2015-2018 compared with the 1951-1980 average $^{82}$, making this period the hottest since observations began in 1880. Thus, it is also important to study the impact of this rise in global temperature over the EIO to better understand tropical ocean response to such short-term changes. 
Table 3. Details of data used in the study.

\begin{tabular}{llll}
\hline S. No. & Parameter & Dataset & Resolution \\
\hline 1 & Sea-level anomalies (SLA) & CMEMS & $0.25 \times 0.25$, daily \\
2 & Ocean heat content (OHC) & Hadley Observations (EN4) & $1 \times 1$, monthly \\
3 & Dynamic height (DH) & Hadley Observations (EN4) & $1 \times 1$, monthly \\
4 & $20^{\circ} \mathrm{C}$ isotherm depth (D20) & Hadley Observations (EN4) & $1 \times 1$, monthly \\
5 & ARGO data (Temp, Salt) & INCOIS & Profiles, daily \\
\hline
\end{tabular}

\section{METHODS}

We used delayed-time (reprocessed) daily SLA data for the 1993-2015 period with a spatial resolution of $0.25^{\circ}$, obtained from Copernicus Marine Environment Monitoring Service (CMEMS) ${ }^{83}$. These data are derived from various satellite missions using an altimeter, and they contain Jason-3, Sentinel-3A, HY-2A, Saral/AltiKa, Cryosat-2, Jason-2, Jason-1, T/P, ENVISAT, GFO, and ERS1/2. The Ssalto/Duacs altimeter products were produced and distributed by the CMEMS (http://www.marine.copernicus.eu). In the present analysis, we have used monthly averages computed from the daily CMEMS data. Moreover, monthly interpolated temperature and salinity profiles from Met Office Hadley Centre observations (EN4) datasets $^{84}$ are used to compute $\mathrm{D} 20, \mathrm{DH}$, and $\mathrm{OHC}$ with respect to $300 \mathrm{~m}$ during the study period. This EN4 version of data is qualitycontrolled and has the spatial resolution of $1^{\circ}$, with 42 depth levels ranging from 5 to $5250 \mathrm{~m}^{84}$. SLA data were regridded to the EN4 grid to carry out the analyses over $10^{\circ} \mathrm{S}-10^{\circ} \mathrm{N}$ and $40^{\circ} \mathrm{E}-100^{\circ} \mathrm{E}$. OHC is derived from the surface to $300 \mathrm{~m}$ of the ocean subsurface using equation $(1)^{49}$

$\mathrm{OHC}=\rho C_{\mathrm{p}} \int_{\text {surface }}^{300} T \cdot d z$

where $\rho$ is the density of the seawater approximated as $1024.5 \mathrm{~kg} / \mathrm{m}^{3}, C_{\mathrm{p}}$ the specific heat capacity at constant pressure considered as $4000.5 \mathrm{~J} / \mathrm{kg} /$ ${ }^{\circ} \mathrm{C}$, and $T$ the temperature $\left({ }^{\circ} \mathrm{C}\right)$ of each layer of $d z$ thickness. Thus, $\mathrm{OHC}$ is here measured as $\mathrm{J} / \mathrm{m}^{2}$. DH with respect to $300 \mathrm{~m}$ is computed from the hydrostatic equation, and it has the expression for depth $z$ as a function of pressure as follows:

$\mathrm{DH}=-\frac{1}{g} \int_{p_{\mathrm{o}}}^{p} \frac{1}{\rho} \cdot d p$

where $p_{\mathrm{o}}$ is the standard pressure at the reference level, $p$ is the actual pressure at the reference level, $g$ is the gravitational acceleration, and $\rho$ is the density of the seawater, a function of temperature, salinity, and depth. A standard method with a salinity of 35 practical salinity units (PSU) and temperature $0{ }^{\circ} \mathrm{C}$ with respect to $300 \mathrm{~m}$ depth is used to compute the height of the water column as a reference value at a location, which is in units of dynamic meters ${ }^{66}$. DH is the difference, or the anomaly, between the height of the water column computed from the actual temperature and salinity values at a location, and the standard reference value at the same location. Typically, DH has a range of $1-2 \mathrm{~m}$. We consider $300 \mathrm{~m}$ as the reference depth to compute $\mathrm{DH}$ and $\mathrm{OHC}$ because sea-level fluctuations at the equator reflect density changes above $400 \mathrm{~m}^{85}$. On the other hand, most of the upper-ocean processes and variability in the EIO are confined to the top $300 \mathrm{~m}$. Moreover, no large biases were observed in the $\mathrm{DH}$ and in the geostrophic currents computed with respect to 300 and $700 \mathrm{~m}$ along the $4^{\circ} \mathrm{N}$ transect ${ }^{66}$. Last, D20 is the depth of $20^{\circ} \mathrm{C}$ below the ocean surface.

Daily observations from 10 ARGO platforms ${ }^{62,86}$ deployed by Japan, over the central EIO, are used in this study to find the relationships between SLA and other upper-ocean parameters. These data are obtained from the Indian National Center for Ocean Information Services (INCOIS) ${ }^{87}$. INCOIS is the regional agency that controls different ocean-observing platforms deployed by India and other countries in the Indian Ocean. INCOIS is also responsible to archive the data from all the sources available, and distributes the same to users around the world ${ }^{88}$. This database comprises in situ, remote-sensing, outputs from the different ocean models and reanalysis datasets of several direct and derived parameters of the Indian Ocean in different temporal and spatial scales. INCOIS also maintains a liveaccess server (http://las.incois.gov.in/las) ${ }^{89}$ that makes data accessible to users around the world. In this work, we used temperature and salinity data available from 10 ARGO floats having the tracks close to the central EIO $\left(10^{\circ} \mathrm{S}-5^{\circ} \mathrm{N}\right)$. All the floats are represented with World Meteorological Organization (WMO) IDs, and they are ordered starting from 2900672 to

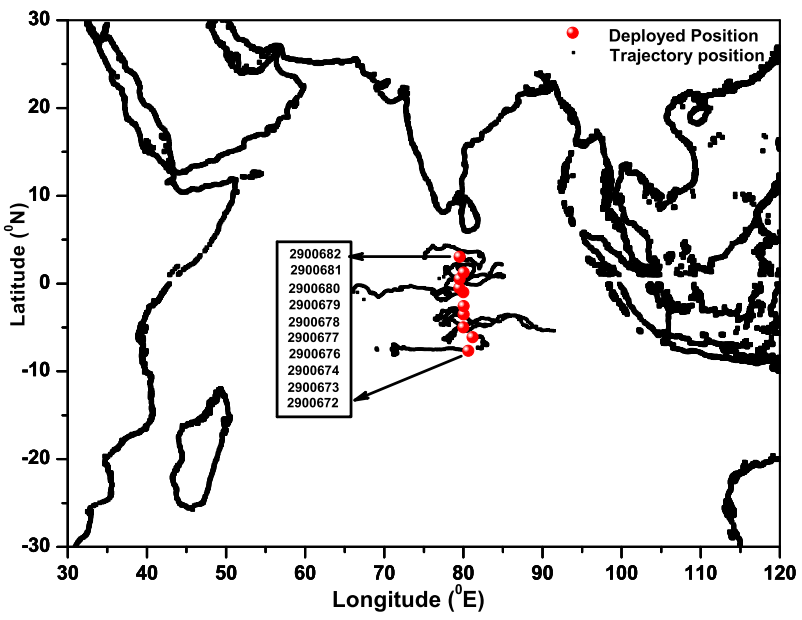

Fig. 8 Position of the ARGO floats in the central EIO $\left(10^{\circ} \mathrm{S}-5^{\circ} \mathrm{N}\right)$ marked in red-color dots. Black lines show their trajectories. The rectangular box shows the corresponding float numbers ordered from north to south.

2900682 (2900675 is missing/not assigned in these sets of floats) from south to north. We have used quality-controlled data to compute $\mathrm{DH}$ and other upper-ocean parameters. Full details of the data used are shown in Table 3. Locations of the ARGO floats used are shown in Fig. 8.

The spatial mean and standard deviations are used to quantify the spatial variability of all these upper-ocean parameters. Seasonal mean and standard deviations are instead used to assess the seasonal variability. Since our aim is to study the linear relationship between SLA and DH, D20, and $\mathrm{OHC}$, we have used Pearson's correlations. Observations from ARGO profiles during the study period are also used to further explore SLA variability along with $\mathrm{DH}, \mathrm{D} 2 \mathrm{O}$, and $\mathrm{OHC}$. Prompted by the results of Ali and Sharma ${ }^{67}, 23$-year monthly data are used to quantify the temporal variability of SLA averaged over $5^{\circ} \mathrm{S}-5^{\circ} \mathrm{N}$ along $40^{\circ} \mathrm{E}-100^{\circ} \mathrm{E}$ in the EIO to find the persistence of east-west oscillations of SLA and the steady central EIO. We divided the study period into two: $1993-2005$ and 2006-2015, to find the mean monthly trends using the changes in slopes of SLA. The equation for a given trend is given as follows:

Trend $=$ slope $\times P+$ intercept

where slope is estimated as the change in a given parameter along $P . P$ is a spatial or temporal variable or an axis.

The choice of these two periods is justified by a significant rise in the EIO SLA from 2006, as shown in Fig. 5. The rationale behind the selection of different periods also matches previous studies 69 , and the period 2006-2015 is also affected by large-scale forcing such as the Pacific Decadal Oscillation, which has a strong effect on the equatorial winds. The two periods also helped to study the decadal variability of SLA in the EIO.

\section{DATA AVAILABILITY}

All the data used in the study are freely available online from the corresponding data sources cited in the article. However, the data that support the findings of this study are available on request from the corresponding author. 


\section{CODE AVAILABILITY}

All codes used in this study are available on request from the corresponding author.

Received: 19 September 2019; Accepted: 21 May 2020;

Published online: 06 July 2020

\section{REFERENCES}

1. Saji, N. \& Yamagata, T. Possible impacts of Indian Ocean dipole mode events on global climate. Clim. Res. 25, 151-169 (2003).

2. Goswami, B. B. et al. Simulation of monsoon intraseasonal variability in NCEP CFSv2 and its role on systematic bias. Clim. Dyn. 43, 2725-2745 (2014).

3. Saji, N., Goswami, B., Vinayachandran, P. \& Yamagata, T. A dipole mode in the tropical Indian Ocean. Nature 401, 360-363 (1999).

4. Webster, P. J., Moore, A. M., Loschnigg, J. P. \& Leben, R. R. Coupled oceanatmosphere dynamics in the Indian Ocean during 1997-98. Nature 401, 356-360 (1999).

5. Philander, S. El Niño, La Niña, and the Southern Oscillation 293 (Academic, San Diego, CA, 1990).

6. Schott, F. A., Xie, S.-P. \& McCreary, J. P. Indian Ocean circulation and climate variability. Rev. Geophys. 47, RG1002, https://doi.org/10.1029/2007RG000245 (2009).

7. Ashok, K., Behera, S. K., Rao, S. A., Weng, H. \& Yamagata, T. El Niño Modoki and its possible teleconnection. J. Geophys. Res. Oceans 112, C11007, https://doi.org/ 10.1029/2006JC003798 (2007)

8. Ashok, K., Guan, Z. \& Yamagata, T. Impact of the Indian Ocean dipole on the relationship between the indian monsoon rainfall and ENSO. Geophys. Res. Lett. 28, 4499-4502 (2001).

9. Ashok, K., Guan, Z. \& Yamagata, T. A look at the relationship between the ENSO and the Indian Ocean dipole. J. Meteorol. Soc. Jpn. Ser. II 81, 41-56 (2003).

10. Weng, H., Ashok, K., Behera, S. K., Rao, S. A. \& Yamagata, T. Impacts of recent El Niño Modoki on dry/wet conditions in the Pacific rim during boreal summer. Clim. Dyn. 29, 113-129 (2007).

11. De Deckker, P. The Indo-Pacific Warm Pool: critical to world oceanography and world climate. Geosci. Lett. 3, 20 (2016).

12. Nagamani, P. et al. Heat content of the Arabian Sea mini warm pool is increasing. Atmos. Sci. Lett. 17, 39-42 (2016).

13. Srinivasu, U. et al. Causes for the reversal of North Indian Ocean decadal sea level trend in recent two decades. Clim. Dyn. 49, 3887-3904 (2017).

14. Shankar, D., Vinayachandran, P. \& Unnikrishnan, A. The monsoon currents in the north Indian Ocean. Prog. in Oceanogr. 52, 63-120 (2002).

15. Wyrtki, K. An equatorial jet in the Indian Ocean. Science 181, 262-264 (1973).

16. Chongyin, L. \& Mingquan, M. The influence of the Indian Ocean dipole on atmospheric circulation and climate. Adva. Atmos. Sci. 18, 831-843 (2001).

17. Sreenivas, P., Gnanaseelan, C. \& Prasad, K. Influence of El Niño and Indian Ocean dipole on sea level variability in the bay of bengal. Global Planet. Change $\mathbf{8 0}$, 215-225 (2012)

18. Sayantani, O. \& Gnanaseelan, C. Tropical Indian Ocean subsurface temperature variability and the forcing mechanisms. Clim. Dyn. 44, 2447-2462 (2015).

19. Gent, P. R., O'Neill, K. \& Cane, M. A. A model of the semiannual oscillation in the equatorial Indian Ocean. J. Phys. Oceanogr. 13, 2148-2160 (1983).

20. Gadgil, S., Vinayachandran, P. \& Francis, P. Droughts of the Indian summer monsoon: role of clouds over the Indian Ocean. Curr. Sci. 85, 1713-1719 (2003).

21. Momin, I. M. et al. Simulated heat content variability in the upper layers of the tropical Indian Ocean. Mar. Geod. 35, 66-81 (2012).

22. Rio, M.-H. \& Hernandez, F. A mean dynamic topography computed over the world ocean from altimetry, in situ measurements, and a geoid model. J. Geophys. Res. Oceans 109, C12032, https://doi.org/10.1029/2003JC002226 (2004).

23. Forget, G. Mapping ocean observations in a dynamical framework: a 2004-06 ocean atlas. Journal of Physical Oceanography 40, 1201-1221 (2010).

24. Guinehut, S., Le Traon, P.-Y. \& Larnicol, G. What can we learn from global altimetry/hydrography comparisons?. Geophys. Res. Lett. 33, L10604, https://doi.org/ 10.1029/2005GL025551 (2006).

25. Thandlam, V. \& Rahaman, H. Evaluation of surface shortwave and longwave downwelling radiations over the global tropical oceans. SN Appl. Sci. 1, 1171 (2019).

26. Wilson, C. \& Coles, V. J. Global climatological relationships between satellite biological and physical observations and upper ocean properties. J. Geophys. Res. Oceans 110, C10001, https://doi.org/10.1029/2004JC002724 (2005).

27. Nerem, R. et al. Climate-change-driven accelerated sea-level rise detected in the altimeter era. Proc. Natl Acad. Sci. USA 115, 2022-2025 (2018).

28. Han, W. et al. Patterns of Indian Ocean sea-level change in a warming climate. Nat. Geosci. 3, 546 (2010).
29. Bindoff, N. L. et al. Observations: oceanic climate change and sea level. Observations: oceanic climate change and sea level. In: Solomon, S., Qin, D., Manning, M., Chen, Z., Marquis, M., Averyt, K. B., Tignor, M. and Miller, H. L. (eds.) Climate Change 2007: The Physical Science Basis: Contribution of Working Group I to the Fourth Assessment Report of the Intergovernmental Panel on Climate Change. pp. 385-433 (Cambridge University Press, Cambridge, UK, 2007).

30. Loeb, N. G. et al. Observed changes in top-of-the-atmosphere radiation and upper-ocean heating consistent within uncertainty. Nat. Geosci. 5, 110 (2012).

31. Allan, R. P. et al. Changes in global net radiative imbalance 1985-2012. Geophys. Res. Lett. 41, 5588-5597 (2014).

32. Dai, A. \& Trenberth, K. E. Estimates of freshwater discharge from continents: latitudinal and seasonal variations. J. Hydrometeorol. 3, 660-687 (2002).

33. Meehl, G. A., Hu, A., Arblaster, J. M., Fasullo, J. \& Trenberth, K. E. Externally forced and internally generated decadal climate variability associated with the Interdecadal Pacific Oscillation. J. Clim. 26, 7298-7310 (2013).

34. Kosaka, Y. \& Xie, S.-P. Recent global-warming hiatus tied to equatorial Pacific surface cooling. Nature 501, 403 (2013).

35. England, M. H. et al. Recent intensification of wind-driven circulation in the Pacific and the ongoing warming hiatus. Nat. Clim. Change 4, 222 (2014).

36. Maher, N., Gupta, A. S. \& England, M. H. Drivers of decadal hiatus periods in the 20th and 21st centuries. Geophys. Res. Lett. 41, 5978-5986 (2014).

37. Drijfhout, S. S. et al. Surface warming hiatus caused by increased heat uptake across multiple ocean basins. Geophys. Res. Lett. 41, 7868-7874 (2014).

38. Meehl, G. A., Arblaster, J. M., Fasullo, J. T., Hu, A. \& Trenberth, K. E. Model-based evidence of deep-ocean heat uptake during surface-temperature hiatus periods. Nat. Clim. Change 1, 360 (2011).

39. Lee, S.-K. et al. Pacific origin of the abrupt increase in Indian Ocean heat content during the warming hiatus. Nat. Geosci. 8, 445 (2015).

40. Unnikrishnan, A. \& Shankar, D. Are sea-level-rise trends along the coasts of the North Indian Ocean consistent with global estimates? Global Planet. Change 57, 301-307 (2007).

41. Milne, G. A., Gehrels, W. R., Hughes, C. W. \& Tamisiea, M. E. Identifying the causes of sea-level change. Nat. Geosci. 2, 471 (2009).

42. Solomon, S., Qin, D., Manning, M., Averyt, K. \& Marquis, M. Climate Change 2007The Physical Science Basis: Working Group I Contribution to the Fourth Assessment Report of the IPCC, vol. 4 (Cambridge University Press, 2007).

43. Woodworth, P. et al. Evidence for the accelerations of sea level on multi-decade and century timescales. Int. J. Climatol. 29, 777-789 (2009).

44. Stammer, D., Agarwal, N., Herrmann, P., Köhl, A. \& Mechoso, C. Response of a coupled ocean-atmosphere model to greenland ice melting. Surveys Geophys. 32 621 (2011).

45. Timmermann, A., McGregor, S. \& Jin, F.-F. Wind effects on past and future regional sea level trends in the southern Indo-Pacific. J. Clim. 23, 4429-4437 (2010).

46. Nidheesh, A., Lengaigne, M., Vialard, J., Unnikrishnan, A. \& Dayan, H. Decadal and long-term sea level variability in the tropical Indo-Pacific Ocean. Clim. Dyn. 41, 381-402 (2013).

47. Aggarwal, D. \& Lal, M. Vulnerability of Indian Coastline to Sea Level Rise (Centre for Atmospheric Sciences, Indian Institute of Technology, New Delhi, 2001).

48. Roxy, M. K. et al. Drying of indian subcontinent by rapid Indian Ocean warming and a weakening land-sea thermal gradient. Nat. Commun. 6, 7423 (2015).

49. Venugopal, T. et al. Statistical evidence for the role of southwestern Indian Ocean heat content in the Indian summer monsoon rainfall. Sci. Rep. 8, 12092 (2018).

50. Aparna, S., McCreary, J., Shankar, D. \& Vinayachandran, P. Signatures of Indian Ocean dipole and El Niño-Southern Oscillation events in sea level variations in the Bay of Bengal. J. Geophys. Res. 117, C10012, https://doi.org/10.1029/ 2012JC008055 (2012).

51. Vinayachandran, P., Francis, P. \& Rao, S. Indian Ocean dipole: processes and impacts. In: Mukunda, N. (ed.) Current Trends in Science. pp. 569-589 (Indian Academy of Sciences, Bangalore, 2009).

52. Neelin, J. D. et al. ENSO theory. J. Geophys. Res. 103, 14261-14290 (1998).

53. Rao, S. A., Behera, S. K., Masumoto, Y. \& Yamagata, T. Interannual subsurface variability in the tropical Indian Ocean with a special emphasis on the Indian Ocean dipole. Deep Sea Res. Pt II 49, 1549-1572 (2002).

54. Mohapatra, S., Gnanaseelan, C. \& Deepa, J. Multidecadal to decadal variability in the equatorial Indian Ocean subsurface temperature and the forcing mechanisms. Clim. Dyn. 1-13 (2020).

55. Shankar, D. Low-Frequency Variability of Sea Level along the Coast of India. Ph.D. thesis, Goa University (1998).

56. Srinivas, K., Kumar, P. \& Revichandran, C. ENSO signature in the sea level along the coastline of the Indian subcontinent. Ind. J. Marine. Sci. 34, 225-236 (2005).

57. Rejeki, $\mathrm{H}$. et al. The effect of ENSO to the variability of sea surface height in western Pacific Ocean and eastern Indian Ocean and its connectivity to the Indonesia Throughflow (ITF). In IOP Conference Series: Earth and Environmental Science, vol. 55, 012066 (IOP Publishing, 2017). 
58. Deepa, J., Gnanaseelan, C., Kakatkar, R., Parekh, A. \& Chowdary, J. The interannual sea level variability in the Indian Ocean as simulated by an ocean general circulation model. Int. J. Clim. 38, 1132-1144 (2018).

59. Annamalai, $\mathrm{H}$. et al. Coupled dynamics over the Indian Ocean: spring initiation of the zonal mode. Deep Sea Res. Pt II 50, 2305-2330 (2003).

60. H, R., Behringer, D. W., Penny, S. G. \& Ravichandran, M. Impact of an upgraded model in the NCEP global ocean data assimilation system: the tropical Indian Ocean. J. Geophys. Res. 121, 8039-8062 (2016).

61. Rahaman, H. et al. Improved ocean analysis for the Indian Ocean. J. Oper. Oceanogr. 12, 16-33, https://doi.org/10.1080/1755876X.2018.1547261 (2019).

62. Gould, J. et al. Argo profiling floats bring new era of in situ ocean observations. EOS, Transactions American Geophysical Union 85, 185-191 (2004).

63. Rebert, J.-P., Donguy, J.-R., Eldin, G. \& Wyrtki, K. Relations between sea level, thermocline depth, heat content, and dynamic height in the tropical Pacific Ocean. J. Geophys. Res. 90, 11719-11725 (1985).

64. Wyrtki, K. \& Kendall, R. Transports of the Pacific equatorial countercurrent. J. Geophys. Res. 72, 2073-2076 (1967).

65. O'Brien, J. J., Busalacchi, A. \& Kindle, J. Ocean Models of El Nino (John Wiley and Sons, 1981).

66. Thandlam, V. \& Udaya Bhaskar, T. An alternate and a better approach to estimate geostrophic velocities in the Bay of Bengal in the absence of salinity profiles. Int. J. Oceans Oceanogr. 12, 29-41 (2018).

67. Ali, M. \& Sharma, R. Elnino type of phenomenon in the equatorial Indian Ocean. World Meteorological Organization-Publications-WCRP-91, WMO/TD-No 717. 1, 403-407 (1995).

68. Hermes, J. \& Reason, C. Annual cycle of the South Indian Ocean (SeychellesChagos) thermocline ridge in a regional ocean model. J. Geophys. Res. 113, C04035, https://doi.org/10.1029/2007JC004363 (2008).

69. Deepa, J. et al. The tropical Indian Ocean decadal sea level response to the Pacific Decadal Oscillation forcing. Clim. Dyn. 52, 5045-5058 (2019).

70. Yu, L. Variability of the depth of the $20 \mathrm{C}$ isotherm along $6 \mathrm{~N}$ in the Bay of Bengal: its response to remote and local forcing and its relation to satellite $\mathrm{SSH}$ variability. Deep Sea Res. Pt II 50, 2285-2304 (2003).

71. Vinayachandran, P., Kurian, J. \& Neema, C. Indian Ocean response to anomalous conditions in 2006. Geophys. Res. Lett. 34, L15602 (2007).

72. Vialard, J., Foltz, G., Mcphaden, M. J., Duvel, J.-P. \& de Boyer Mont,gut, C. Strong Indian Ocean sea surface temperature signals associated with the Madden-Julian Oscillation in late 2007 and early 2008. Geophys. Res. Lett. 35, L19608, https://doi. org/10.1029/2008GL035238 (2008).

73. Niiler, P. \& Stevenson, J. The heat budget of tropical ocean warm-water pools. J. Mar. Res. 40, 465-480 (1982).

74. Wyrtki, K. Water displacements in the Pacific and the genesis of El Niño cycles. J. Geophys. Res. 90, 7129-7132 (1985).

75. Fu, L.-L. Intraseasonal variability of the equatorial Indian Ocean observed from sea surface height, wind, and temperature data. J. Phys. Oceanogr. 37, 188-202 (2007).

76. Chen, G. \& Quartly, G. D. Annual amphidromes: a common feature in the ocean? IEEE Geosc. Remote Sens. Lett. 2, 423-427 (2005).

77. Durand, F., Alory, G., Dussin, R. \& Reul, N. Smos reveals the signature of Indian Ocean dipole events. Ocean Dyn. 63, 1203-1212 (2013).

78. Iskandar, I. et al. What did drive extreme drought event in Indonesia during boreal summer/fall 2014? In Journal of Physics: Conference Series, vol. 817, 012073 (IOP Publishing, 2017).

79. Cheng, L. et al. Improved estimates of ocean heat content from 1960 to 2015. Sci. Adv. 3, e1601545 (2017).

80. Cane, M. A. Modeling sea level during El Niño. J. Phys. Oceanogr. 14, 1864-1874 (1984).

81. Thompson, B., Gnanaseelan, C. \& Salvekar, P. Variability in the Indian Ocean circulation and salinity and its impact on SST anomalies during dipole events. J. Marine Res. 64, 853-880 (2006).

82. Duncombe, J. 2018 is the fourth-hottest year on record. https://eos.org/articles/ 2018-is-the-fourth-hottest-year-on-record (2019).

83. Rosmorduc, V., Bronner, E., Maheu, C. \& Mertz, F. Aviso: altimetry products and services in 2013. In EGU General Assembly Conference Abstracts, vol. 15 (2013).

84. Good, S. A., Martin, M. J. \& Rayner, N. A. En4: Quality controlled ocean temperature and salinity profiles and monthly objective analyses with uncertainty estimates. J.Geophys. Res. 118, 6704-6716 (2013).

85. Wyrtki, K. \& Kilonsky, B. Mean water and current structure during the Hawaii-toTahiti shuttle experiment. J. Phys. Oceanogr. 14, 242-254 (1984).
86. Davis, R., Sherman, J. \& Dufour, J. Profiling ALACEs and other advances in autonomous subsurface floats. J. Atmos. Oceanic Technol. 18, 982-993 (2001).

87. Geetha, G., Bhaskar, T. \& Rao, E. P. R. Argo data and products of Indian Ocean for low bandwidth users. Int. J. Oceans. Oceanogr. 5, 1-8 (2011).

88. Rao, E. P. R. et al. Marine Data Services at National Oceanographic Data CentreIndia. Data Sci. 17, 11, https://doi.org/10.5334/dsj-2018-011 (2018).

89. Devender, R., Udaya Bhaskar, T., Pattabhi Rama Rao, E. \& Sathyanarayana, B. INCOIS live access server: a platform for serving the geospatial data of Indian Ocean. Int. J. Oceans Oceanogr. 7, 143-151 (2013).

\section{ACKNOWLEDGEMENTS}

The authors wish to thank Met Office, UK for providing EN4 observation data, and Indian National Center for Ocean Information Services (INCOIS), India for providing ARGO observations. The authors acknowledge the Argo data used in this paper, and these data were collected and made freely available by the International Argo Program and the national programs that contribute to it (http://www.argo.ucsd.edu, http://argo.jcommops.org). The Argo Program is part of the Global Ocean Observing System. The authors also thank Copernicus Marine Environment Monitoring Service (CMEMS) for providing SLA data. The authors also acknowledge the Department of Earth Sciences, Uppsala University, Uppsala Sweden, and INCOIS, India for the support and help to carry out this work. The authors acknowledge the research grant from Swedish Research Council (VR). Thanks to PyFerret software from NOAA, which was used to carry out data analysis, visualization, and to produce figures. We thank anonymous reviewers whose comments and suggestions have helped us to improve the paper. Open access funding provided by Uppsala University. This is INCOIS contribution number 381 .

\section{AUTHOR CONTRIBUTIONS}

V.T. conceived the research plan, performed data analysis, and prepared the first draft, T.V.S. helped to improve the research plan and figures, and H.R. contributed to analyze the results. P.D.L. and E.S. helped to improve the paper. All other authors contributed equally to write and review the paper.

\section{COMPETING INTERESTS}

The authors declare no competing interests.

\section{ADDITIONAL INFORMATION}

Supplementary information is available for this paper at https://doi.org/10.1038/ s41612-020-0127-z.

Correspondence and requests for materials should be addressed to V.T.

Reprints and permission information is available at http://www.nature.com/ reprints

Publisher's note Springer Nature remains neutral with regard to jurisdictional claims in published maps and institutional affiliations.

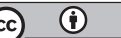

Open Access This article is licensed under a Creative Commons Attribution 4.0 International License, which permits use, sharing, adaptation, distribution and reproduction in any medium or format, as long as you give appropriate credit to the original author(s) and the source, provide a link to the Creative Commons license, and indicate if changes were made. The images or other third party material in this article are included in the article's Creative Commons license, unless indicated otherwise in a credit line to the material. If material is not included in the article's Creative Commons license and your intended use is not permitted by statutory regulation or exceeds the permitted use, you will need to obtain permission directly from the copyright holder. To view a copy of this license, visit http://creativecommons. org/licenses/by/4.0/.

(c) The Author(s) 2020 